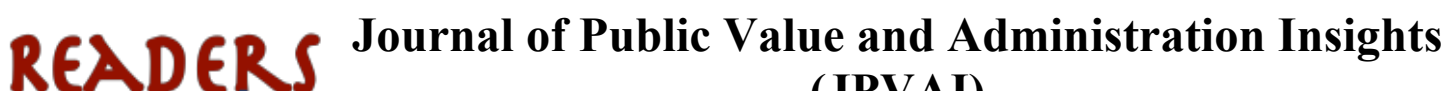 nsight (JPVAI) \\ ISSN: \\ www.readersinsight.net/jpvai
}

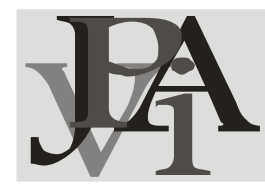

\section{A Study on Effect of Leadership Styles on Employees Performance in Local Courier Company: The Case of "Pos LAJU" in Malaysia}

\author{
MUHAMAD FIKRI BIN FAUZAN
}

Malaysian Institute of Industrial Technology, University Kuala Lumpur

*Corresponding author: Idheathcliff94@gmail.com

\begin{abstract}
Leadership ability have a great impact in organization where it need an effective approach in managing the employee. In courier service company, the excellent of a company is based on the act of a leader where the interactions between employers and employees will determine the direction whether the company will achieve the organization goal or otherwise. This study presents a capable visionary leader influence on employee's performance where the analysis for the employee's performance was conducted to measure the affection on visionary styles. To perform this task Statistical Package for Social Science (SPSS) programs was used to make the analysis.to get the relationship between the visionary leader and employees performance. The result indicates that visionary styles have a positive relationship on employees performance. The analysis finding shows that the job satisfaction, employee engagement and employee attitude have a positive relationship with the visionary leader but only two variable in employee performance is accepted. From the point, we will find that this company have a capable leadership style that can influence employees in Pos Laju Company. The courier services company Pos Laju higher management should use this visionary leadership ability that could influence on their employees to ensure a better affection toward employees performance.
\end{abstract}

Keywords: Leadership, Visionary Style, Employees Performance, Statistical Package For Social Science Programs, Positive Relationship

\section{INTRODUCTION}

Leadership has been well-known and also have a great impact on any group or association where the adoption of a new effective approach to managing mass workers (employee) and organizations. Various types of leadership styles have been implemented in many group or association that responds well to managing employee performance. The personal concept of staff administration is gradually being replaced by human resource management. Additionally, it will provide more important benefits to the strategic integration of new leadership styles ineffective employee management and improve employee performance.

The powerful leader should be an amazing diagnostician and adopt a style to fulfill the demands of the scenario wherein they operate (Kenneth and Hersey, 1998, Ali et al., 2018). Others that, it's going to replicate at the character itself as a pacesetter to implement it which if they in different situation and scenario. Every individual behavior including the employees has a different perspective that requires a different trait for them to communicate with the working group. Different leadership styles are used appropriately for employees to improve their performance and to meet the needs of employees based on the number of instructions, empowerment, and decision-making powers.

Based on figure 1.1 below, it has been shown that circumstance of leadership styles that give different trait from a different perspective. This figure was taken from the "Seven Levels of Personal Consciousness" and the "Seven Levels of Organizational Consciousness" at the valuescenter.com.

\section{ARTICLE INFORMATION}

Received: 1 July 2018

Revised: 1 November 2018

Accepted: 13 November 2018

\section{DOI:}

10.31580/jpavi.v1i1.138

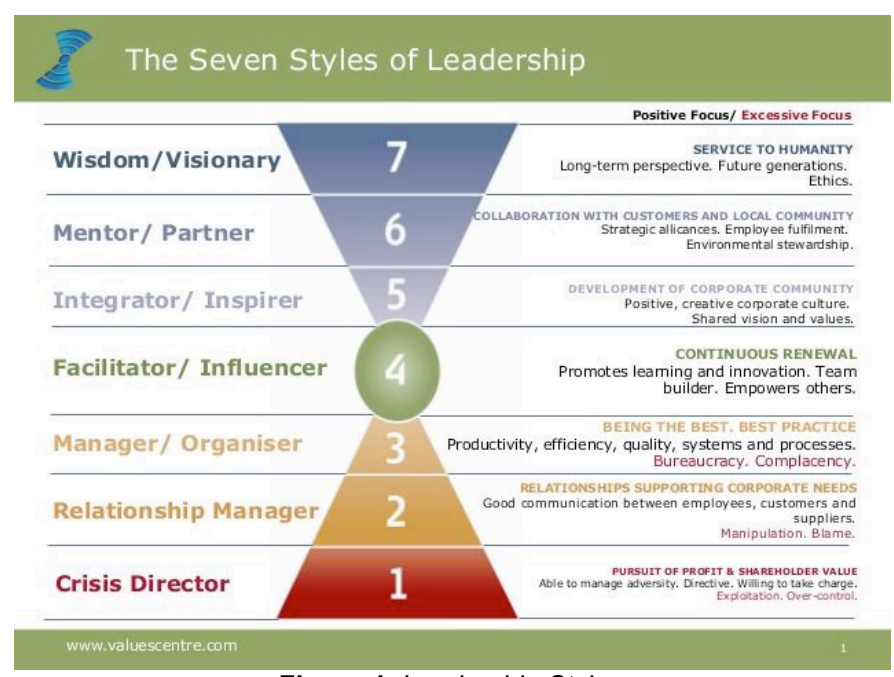

Figure 1: Leadership Styles

This research study is to know and discusses the effect of leadership styles that can give big influence on organization mostly on employee's performance in Courier Services Company. The company that was chosen by the researcher was a Pos Laju company in Pasir Gudang, Johor, Malaysia.

Pos Laju is one of courier Services Company that operated in Malaysia which include in Pasir Gudang as one of their branches. It was known as a Pos Malaysia Berhad. Pos Laju provides domestic courier services and international courier services through 50 courier centers supported by Pos Malaysia's retail network. Pos Laju also 
provides value-added services to complement its services such as services on insurance packages, packaging solutions, and web-based tracking. Pos Laju also provides door-to-door service and customers can choose to send documents or parcels using "Next Day Delivery", "Same Day Same Day" and "Certain Time Services" to local and international destinations.

This courier services company was established in 1986 by delivering international mail under the Expedited Mail Service (EMS) banner for Pos Malaysia Berhad. In 1988, it began to offer domestic courier services under the Pos Laju brand name. After 20 years in business, Pos Laju is now undisputed as the main courier and express mail service provider in the country. Every year, Pos Laju has shown strong growth in volume and revenue reflecting the level of confidence and trust provided by their supporter and customers. This is because of the impact of the leadership styles which been implemented at this company gives a big influence on employee's performance for them to make this courier company strive and achieved their company goal.

Shafie et al. (2013) explain the importance of leadership in organizations and especially in human beings who seem to be the largest asset of any firm. He also stated that "The organizers of the organization are usually employee's, they give life to the organization and provide the goal". Leadership can give more credibility to employee's performance whether they can improve the quality of the organization and manage to strive forward to their organization goal in order to grow or just follow the organization standard procedures. Especially in courier Service Company, a leader need to give clear direction and accurate information to their employee's so they can do a better job without making mistake.

In a courier service company, there are problems and benefits that can give impact on the organization future mostly from the leadership qualities. Each distinct leadership feature will show different results on employee performance. The development of a company is based on internal management where interactions between employers and employees will determine the direction of whether the company will achieve the organization goal or otherwise.

The researcher made an observation and uses their services and found that the case company have advantages and disadvantages in their management. We can see this issue based on customer feedback (See Figure 1.3) and on their social working environment that gave impact on their services provided to their customer. This might be from miscommunication or interaction or misleading leadership capability to conduct their employees. From the researcher observation, the researcher realizes that the Pos Laju courier company are able to show a strong growth by maintaining their services even though they struggle to pass customer satisfaction level.

The researcher will make a study to know if there has a useful leadership ability conduct in this company especially on their higher management. This will indicate whether this company has a capable leadership that can influence their employees. So, the researcher made a study on how effective leadership styles that will give impact on employee's performance at the courier company.

This paper explains the objectives of the research which is a basic tool to underline all planning. The objective of this research is based on the problem statement. The objective consists:

i. To identify leadership styles that capable influence employee's performance.

ii. To analyse the employee's performance affected by the chosen leadership ability.

This study will be conducted at Pos Laju Pasir Gudang, Johor. This research scope is concentrated on the company worker from manager/supervisor to the ordinary worker (respondent) related to the employee's performance that was influenced by the leadership styles. It is very important to identify the best and appropriate leadership styles in the company. It will relate to developing the employee's productivity which can improve a company profile and will attract more customer to use this company services. The potential respondents are only for the Pos Laju employee's and not include the customer. Moreover, the research area is only limited in Pos Laju Pasir Gudang area.

\section{LITERATURE REVIEW}

This research study will assess the researcher in knowing the effect of leadership styles which on researcher choose whether it been implemented more or less in the company and the effect on employee's performance at the courier company. This will give the researcher some experience and gain more knowledge in order to conduct the research study for future use.

On the company's perspective (Pos Laju), this research can help them to increase organizational productivity and also increase their business performance. It is easier for them to correct some errors or problems within the company. It will generate positive ties among employees in the company.

From the worker perspective, this research will encourage them to make a change (attitudes, awareness, moral and ethics) for themselves. It can improve their working performance by lending them a little bit of knowledge. This research might help to strengthen the relationship among workers (employee's and employer).

For the customer perspectives, they will get a better service as the company makes a positive change. Customer will continue to use their services which if can give benefit to them and also to the courier company. The feeling of satisfaction on the customer is increasing if they manage to maintain and provide better courier services to hold last longer.

In general, the notion of leadership and function is divided into several points. Among them are maintaining integration and coordination within an organization in order to run effectively, initiating organizational structure, overcoming conflict and emerging conflicts, conducting evaluation and re-evaluation, formulating organizational or institutional goals and determining efficient means and means to achieve and also make changes, revisions, development innovations and improvements within the organization.

According to (Iqbal, 2015), leadership is a procedure by which can direct, influence and manage work of others toward the achievement of particular objectives in which the ability of a manager to prompt the subordinates to work with certainty and enthusiasm. The person with leadership behavior needed to construct and develop a vision to improve the performance of subordinates in order to give the member in the organization some motivation. As indicated by (Adair, 2015), "Leadership is the ability to convince others to decided goals. It also stated that leadership can persuade people or other in order to improve their performance and lead them to achieve goals. There's more quote from Adair which said "when someone finds vision and mission of his life, when there is inner peace and forming a solid character building, when every speech and action begins to affect his environment, and when his existence pushes change in his organization, that's when a person is born into a true leader."

Being a leader is also a lot of challenges, therefore it needs to be mentally positive to other people, to change, or maybe to the future. Consciously or unconsciously, the style of human leadership is different from each other, even different in different occasions and situations. Whatever leadership style chooses, the goal is to achieve success with the group that needs to lead. Leadership needs to be supported also by a number of other factors in order to build the dream of the team itself. Other same vision, work plan by holding the code of ethics, mutual empowerment, the task delegation, and appreciation for the performance of colleagues. Even termination of cooperation with colleagues who do not perform well is also legitimate. Only a strong character leader has the firmness and fairness to maximize his teamwork. Sami et al. 2016 proved that ethical leaders plays an important role to create public value in public sector organization.

The powerful leader should be an amazing diagnostician and adopt a style to fulfill the demands of the scenario wherein they operate (Kenneth and Hersey, 1998). This situation and scenario have been stated in chapter one in this research study as generally which it explains on every individual behavior including the employees have a different perspective that requires a different trait for them to communicate within the working group. Different leadership styles are used appropriately for employees to improve their performance and to 
meet the needs of employees based on the number of instructions, empowerment, and decision-making powers.

Moreover, (Awan, 2009) also cited the definition of leadership which is the leadership is main of the most observed phenomenon in this modern organization. There are various definitions that can be thought of leadership. These definitions contrast because they are centered on various measurements of buildings. Some highlight the relationship between pioneers and other collaborators of pioneers and other supporters, some above others, and some in the dynamic collaboration. (Armstrong, 2012) Characterized a leadership as a procedure for motivating individuals to do their best so as to accomplish the wanted outcome. He expressed this includes creating and imparting a dream for the future, rousing individuals and securing engagement. This is a useful understanding for leaders to know their roles to conduct and to lead themselves effectively.

Chen (2008), has cited leadership in his studies in which he has identified different types of leadership styles led by leaders within an organization. Each type of styles conducts many types of different trait which can influence the employee's morale. These also include on the job satisfaction of an individual in the organization, employee's engagement and also influence the employee's attitudes toward the employee's performance and organizational performance.

(Shafie, 2013) is stated again in this chapter which explained the importance of leadership even the leadership in organizations and especially in human beings known as employees who seem to be the largest asset of any organization or association. Leadership can give more credibility to employee's performance whether they can improve the quality of the organization and manage to strive forward to their organization goal in order to grow or just follow the organization standard procedures. Especially in courier Service Company, a leader need to give clear direction and accurate information to their employee's so they can do a better job without making mistake.

Different leadership styles can influence the organization's ability or performance and produce a different result from different traits. The difficulty of leadership styles to implement bring an interesting subject for many researchers. The ongoing look for suitable leaders has resulted in the development of many leadership theories. Research has been performed to decide how leadership behaviors may be used to steer personnel for advanced organizational effects.

There are numerous forms of leadership which not every person is of the same opinion that a specific fashion of leadership will bring about the handiest form of organizational conduct (Mosadeghrad 2008). Distinct leadership styles were needed in every situation depending on how the environment works in order to realize the specific method of leadership styles used for getting a better result. Leadership style is good for every situation seeing that a leader can also have expertise and capabilities to act correctly in a single situation but might not end up efficaciously in a different situation.

The coaching or known as mentor styles function when involved in teaching and supervise a follower. This type of leadership is highly operating to settings results or some performance that really require improvement. This leadership styles motivates, encourages and inspires the followers. Simply, followers are helped to improving their own skills.

A word from (Northcutts, 2009) said, mentoring will represent the experienced worker providing an expert recommendation to a more youthful employee, even as serving as a teacher or a counselor. Functioning as a mentor is different from being a coach. A coach is someone who helps someone to achieve the goal. The characteristic of a mentor isn't accurate and remediate work conduct. The role of a mentor is to provide professional advice and help the employee to apprehend the company culture.

Strangely, quite a bit of what goes for conventional ways to deal with overseeing is apparently experiencing some miscommunication with supporting integrator leaders. The quest for "control" in management and measurement control as unseemly storehouse based execution pointers frequently serve to battle the rise of a culture that uses these Integrator Leaders.
In courier services, this kind of leader will give a stressful condition to subordinates at a certain level even though it can generate positive and creative corporate culture. While an organization loaded up with integrator leaders all pursuing their own particular plans and agenda, paying little mind to how well they line up with the 10,000-foot view procedures and objectives, sounds somewhat like disarray or chaos, not every person or only one out of every odd individual will gravitate to the role of Integrator Leader.

Visionary leaders exist to make a positive vision and motivation for the future and create an exciting vision that can appeal to the conferred believers. Visionary leaders need to understand the importance of themselves and the interests of the advocates, and the need to mobilize the believers to achieve progressive and fostering a future of excellence. This can be stated as some followers are affected by a little knowledge and they can feel solidarity for strong reasons.

(Valenzuela, 2007) said, if some leader has a visionary mindset of collective training and collective commitment to the team, they will make their own followers to hone and stimulate their colleagues with individual consideration. Visionary leadership is a leadership action that can influence or encourage others to create and express a realistic, credible and exciting future vision that can improve the current situation by inspiring minds and maintaining commitment, having good and easy terms and reflecting the uniqueness of the organization and different skills.

Facilitative leadership is opposed to the old fashion of leadership which is authoritative leadership. It is indeed in a new era of piloting a project, team or an organization. The leader needs to be compassionate when communicating which it also includes in listening openly to the verbal and non-verbal expressions of team members, subordinates or clients without judgment or condemnation. This kind of leadership support and open any kind of suggestion and feedback from everyone that collaborate to get or share opinion and though.

(Steve Reilly, 2009) said that a facilitative leadership is making great major positive feelings that will give them a solid feeling of regard and thankfulness for themselves and additionally toward the organization.

Performance is the result of work produced by employees or real behavior that is displayed in accordance with its role in the organization. According to (Yuli, 2009) Job performance is the end result of operating quality and quantity attained by an employee in performing his duties in accordance with the duties or tasks given to him. Employee performance is a very important thing in the organization's efforts to achieve its objectives so that various activities must be done to improve the organization.

One of them is through performance appraisal. Performance appraisal is a process through which organizations evaluate or assess employee performance. (Yuli, 2009) cited the performance appraisal is a process conducted by the organization against employees systematically and formally based on the work assigned to him.

According (Nindyati, 2008), understanding of work performance cannot be separated from the understanding that is multi-dimensional. The willingness and ability of a person in doing the job can be seen from his work performance, in an effort to apply the concepts, ideas, ideas effectively and efficiently so as to achieve goals set by the company.

But this ability is not only in the ability to manage, but lead and apply all the capabilities that exist in him to achieve the goals set together in a "unit" company. Thus, the employee performance means achievement or contribution given by employees in carrying out duties and responsibilities and functions as employees in the company.

In addition, work performance is limited as a result of employee work behavior that supports the achievement of output or achievement and related to the effort to complete the task at a certain period of time. The results reflected in the behavior are influenced among others by motivation.

Job satisfaction is an orientation of feelings that possess each of every employee's towards role they're performing inside the place of the job including the task delight is the essential thing of employee 
motivation and encouragement towards better job performance by (Baah, 2011).

Many human beings have described the process of satisfaction. Another definition from his for job satisfaction is a task satisfaction as the included set of physiological and environmental conditions that inspire personnel to confess that they may be happy or glad about their jobs. In addition, the position of employees in the workplace is emphasized as there is a power of numerous factors on a worker in the association.

(Amoaka 2011) think for the employee were not glad about the undertaking work or task that assigned to them, they are not confirmed by factors including their rights, dangerous working condition, cannot cooperate with each team members, not getting respect from them superior and they're no longer considered within the choice-making process resulting them to have bad experience working with the organization and cut loose the corporation. Nowadays, he highlighted that the corporations cannot have the funds for disillusioned or worst employees as they will now not carry out as much as the expectancies in their supervisor.

For the result, they'll be fired which it ensuring firms to bear additional prices for recruiting new staff. So, it's far beneficial for corporations providing a better and more flexible working environment to the employees where they feel their evaluations are valued and they're part of the organization. Employee morale ought to be in the best condition because it might be pondered in their performance, the employee's with low morale would cause the employees to generated lesser efforts to enhance their working performance.

Employee engagement is an administrative center approach that created a result within the right conditions for all contributors of an enterprise to present of their nice each day, committed to their employer's desires and values, influenced to contribute to organizational success, with an enhanced experience in their own nicely-being. Worker or employee's engagement is based totally on trust, integrity, shows of dedication, and able communicating with a company and its participants.

Employee's engagement can relate to working involvement which is genuinely the employee's engagement was categorized by using countrywide involvement. It somehow specifically equates to the employee's engagement with job satisfaction. (Hakim \& Viwesvaran 2005) named employment engagement as a psychological degree of the paintings-associated from the work begin and paintings had been performed in it and the worker engagement and work dedication that's equally specific.

Engagement is about passion and commitment with the willingness to invest oneself and amplify and to increase one's discretionary effort to assist the organization to succeed, that's past simple pride with the employee association or primary loyalty to the employer (Macey and Schnieder, 2008). The employee engagement calls for management commitment through setting up clear undertaking, vision, and values.

Attitude is known as a mental phenomenon changed of an individual into given formal recognition early in the records of social psychology. The idea's entry into the language of psychology till now, the hobby in attitude has been sturdy and developing (Jackson, 2009). However, through the years attitudes, had been studied with differing emphasis and methods. The idea of mindset which it's far important to be specific in defining attitudes because the kind of posted definitions and descriptions is almost limitless.

Attitudes are known as a people moral behavior that affects the behavior of a person by means of setting the individual to be ready to respond favorably things in his surroundings. Every attitude is obtained through studying over a period of time. The manner of gaining knowledge of attitudes starts right from the adolescence and continues at some stage in the lifestyles of a person. The attitudes are greater essential to human conduct which related to some factors that can trigger the mental phenomenon to change (Jackson, 2009).

For other reason, more tries had been made to research individual attitudes by compared to others. Manifestly, attitudes are a vital attention due to their important function in the manner of remodeling work necessities into efforts. The person mindset alone has no longer have an effect on behavior, however, these acts with different elements within the man or woman influencing behavior, together with persona, belief, motivation, and so forth.

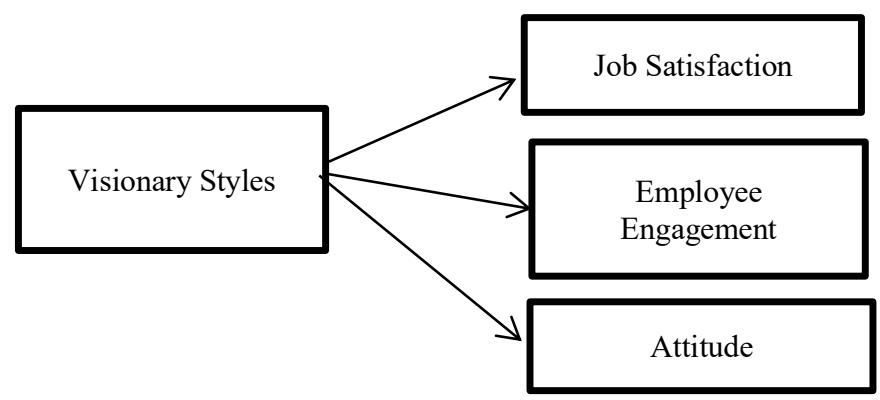

Figure: 2. Conceptual Framework.

On the figure above shows that the theoretical framework which consists of the independent and dependent variable. The dependent variable is about the visionary styles implemented for the researcher to measure the ability of leadership styles in the courier services company. For the independent variable, it shows that the measurement of employees performance which has stated by the researcher which consists of job satisfaction, employee engagement, and employee attitude. This explains which the result of leadership styles will affect the employee's performance which is described in three-part (see figure 2). All of this variable gives influence toward the effect of leadership behavior on employee's performance.

The dependent variable in this research is on the leadership styles. It is the main focus topic for this research study which will give a result on the leadership styles implemented and measured. This study is to find the effectiveness of the leadership styles implemented in the courier services company which is the Pos Laju which is the company branches in the area of Pasir Gudang, Johor. The leadership styles that were the focus here is a visionary leadership style.

All of the leadership styles can be applied to any organization. The reason visionary leadership styles were selected by the researcher because courier service commonly has a motto that places their company future achievement by providing a clear vision and mission as a guide for the leader and underling. Only one leadership is a need for the researchers to manage and conduct the research and also to get easier and instant result.

The independent variable for this research is on the employee's performance. This study was to focus on how the employee's performance is conducted in this research. This is to find on the measurement for employee's performance and it different result from the effect of leadership styles. The measurement of employee performance was described in three part which is job satisfaction, employee engagement, and employee attitude.

\section{METHODOLOGY}

This research will use a quantitative data analysis as to obtain a quantification type of data. To conduct this types of data analysis, the use of a questionnaire is needed. The questionnaire represented a survey form to collect quantitative data analysis from the respondents. This types of data will enable the dissemination of results from the sample to the target respondent and the measurement of the occurrence of various opinions in the sample provided.

Estimate of sample size performed to ensure sample size selection in accordance with the required accuracy. The research takes an important step as consideration before starting any survey. The estimate of sample size is determined by using the Krejcie and Morgan table. It is able to determine the sample size of a known population.

There is no needed for using the sample size formula because the table has all the provision requires getting the number of respondents. Estimated number of respondents required for this research study involves 100 people represented the respondents which is the 
population size is described as $\mathrm{N}=100$ and the sample size is described as $\mathrm{S}=80$. The questionnaire will be distributed to the employees who only work in the Pos Laju Company. The sample size of the population in the Pos Laju company is 52 workers because the population size of people at the courier company is around 60 people.

Researchers analyzed all collected data, calculations, and results produced with graphs and charts using the Statistical Package for Social Science (SPSS). SPSS is known as a computer application that provides statistical data analysis in order to achieve research goals.

\section{RESULTS AND DISCUSSION}

In this demographic section of the survey presented the respondent's background information analysis represented by their position in the company, age, gender, education level and year of services in the company. All the data will be shows using a pie chart.

\begin{tabular}{|c|c|c|c|c|c|}
\hline & & Frequency & Percent & Valid Percent & $\begin{array}{c}\text { Cumulative } \\
\text { Percent }\end{array}$ \\
\hline \multirow[t]{4}{*}{ Valid } & Middle Management & 17 & 32.7 & 32.7 & 32.7 \\
\hline & Subordinates & 30 & 57.7 & 57.7 & 90.4 \\
\hline & Top Management & 5 & 9.6 & 9.6 & 100.0 \\
\hline & Total & 52 & 100.0 & 100.0 & \\
\hline
\end{tabular}

\section{Your Position in the company}

52 responses

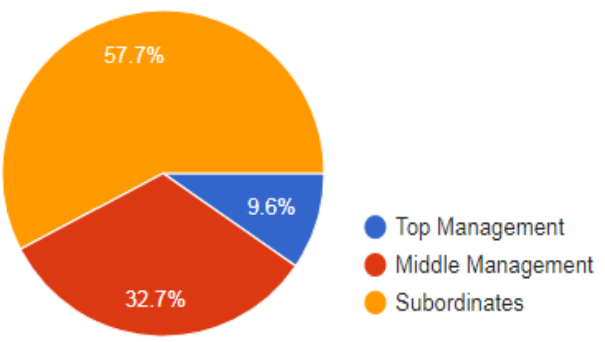

Figure 3: Position in the Company.

The figure above shows that the results of respondents for their current position in the company. Top management respondents show about $9.6 \%$ ( 5 people) hold this position. The middle management respondent with $32.7 \%$ (17 people) was in the position and the remaining is about $57.7 \%$ (30 people) that work as subordinates stated the highest number of respondents in the current position in the courier services company (Pos Laju).

\section{Your Age}
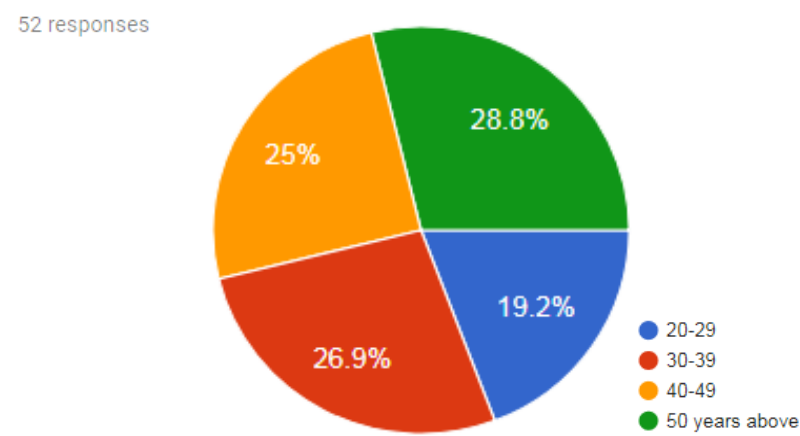

Figure 4: Age.
Above shows the results of respondents for their age. Approximately the age of $20-29$ years old is $19.2 \%$ (10 people) with a lower number of workers working in (Pos Laju) Courier Company. For ages $30-39$ is $26.9 \%$ (14 respondents) working there. The higher number of respondents was at the age of 50 above which stated $28.8 \%$ ( 15 people) and the rest was at age $40-49$ was $25 \%$ (13 people) stated.

\section{Your Gender}

52 responses

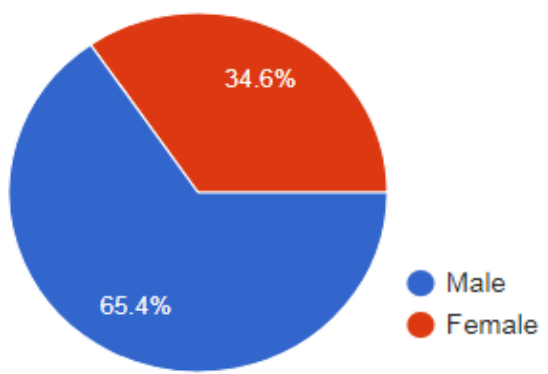

Figure 5: Gender.

The figure above shows the questionnaire that been distributed to the respondent mostly answered by male respondents by $65.4 \%$ (34 people), due to the job was suitable for a male to work in (Pos Laju) courier services company. The remaining is female respondents by $34.6 \%$ (18 people).

\section{Your Highest Level of Education 52 responses}

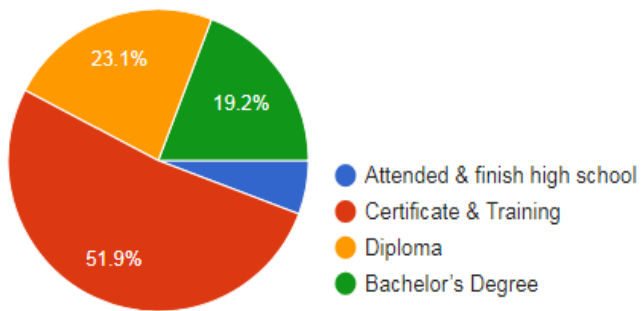

Figure 6: Highest Education Level.

The chart above shows the highest level of respondents' education. The higher results were on 27 respondents working there with certificates and training with $51.9 \%$ followed by 12 respondents with $23.1 \%$ having a diploma. It is indeed for a courier service company to recruit trained workers. The other 10 respondents had a bachelor's degree as a higher level of education with $19.2 \%$ and the lower one was 3 respondents who only attended and completed high school as the highest level of education with $5.8 \%$ stated.

\section{Your Services Years in the company}

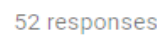

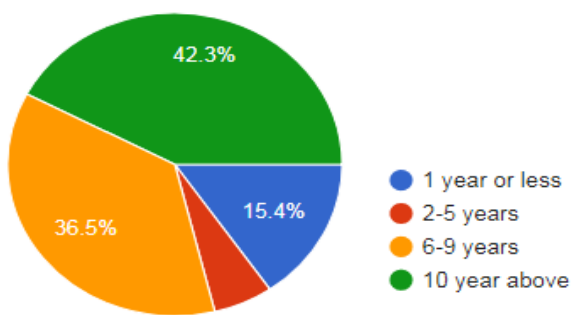

Figure 7: Services Years in the Company. 
According to the figure, it shows that the result of services years of the respondents in the company. The longer services years that stated the higher number is at 50 years above with 22 respondents by $42.3 \%$ have long served in the courier company. The second higher is on 6-9 years of services with 19 respondents by $36.5 \%$ that have served in the company. Other is 1 year or less services in the courier company with 8 respondents by $15.4 \%$ and the lower number is on $2-5$ years of services with 3 respondents served in the courier company.

Researcher will use a regression analysis as a method to measure the relationship of the variable used in this research. This statistical measure will represent the variance part for the dependent variable that will be explained by the independent variable.

\begin{tabular}{|c|c|c|c|c|}
\hline Model & $\mathbf{R}$ & $\begin{array}{c}\text { R } \\
\text { Square }\end{array}$ & $\begin{array}{c}\text { Adjusted R } \\
\text { Square }\end{array}$ & $\begin{array}{c}\text { Std. Error of the } \\
\text { Estimate }\end{array}$ \\
\hline 1 & $.966 a$ & .933 & .928 & .38425 \\
\hline
\end{tabular}

The above table shows the regression data of the research. Based on the table above, its shows that the $\mathrm{R} 2=0.933$. The $\mathrm{R} 2$ represent 93.3\% show that the variation in employees' performance due to independent variable.

ANOVA is known as a collection of statistical models and related procedures that are used to analyze the differences between groups of mean.

Table 3: ANOVA

\begin{tabular}{|c|c|c|c|c|c|c|}
\hline \multicolumn{7}{|c|}{$\begin{array}{c}\text { Table 3: ANOVA } \\
\text { ANOVAa }\end{array}$} \\
\hline & Model & $\begin{array}{l}\text { Sum of } \\
\text { Squares }\end{array}$ & df & $\begin{array}{c}\text { Mean } \\
\text { Square }\end{array}$ & $\mathbf{F}$ & Sig. \\
\hline \multirow{3}{*}{1} & Regression & 98.275 & 3 & 32.758 & 221.914 & $.000 \mathrm{~b}$ \\
\hline & Residual & 7.105 & 48 & .148 & & \\
\hline & Total & 105.381 & 51 & & & \\
\hline
\end{tabular}

b. Predictors: (Constant), job satisfaction, employee engagement, employee attitude

The table above shows the ANOVA table. The table above shows that the $\mathrm{f}$ value is 221.307 . The $\mathrm{f}$ value shown is above the significant level of 1.96, this show the model fitness.

Table 4: Coefficients Coefficients

\begin{tabular}{|c|c|c|c|c|c|c|}
\hline \multirow{3}{*}{ 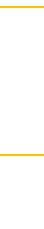 } & \multirow{3}{*}{ Model } & & & \multirow{3}{*}{$\begin{array}{c}\text { Standardiz } \\
\text { ed } \\
\text { Coefficient } \\
\text { s } \\
\text { Beta }\end{array}$} & \multirow{3}{*}{$\mathbf{t}$} & \multirow{3}{*}{ Sig. } \\
\hline & & \multicolumn{2}{|c|}{$\begin{array}{l}\text { Unstandardize } \\
\text { d Coefficients }\end{array}$} & & & \\
\hline & & B & $\begin{array}{l}\text { Std. } \\
\text { Error }\end{array}$ & & & \\
\hline & (Constant) & 4.565 & .108 & & 42.400 & .000 \\
\hline & $\begin{array}{c}\text { Job } \\
\text { Satisfaction }\end{array}$ & .051 & .115 & .060 & .446 & .658 \\
\hline 1 & Employee & & & & & \\
\hline 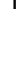 & $\begin{array}{c}\text { Engageme } \\
\mathrm{nt}\end{array}$ & .406 & .180 & .476 & 2.256 & .029 \\
\hline & $\begin{array}{c}\text { Employee } \\
\text { Attitude }\end{array}$ & .430 & .142 & .553 & 3.034 & .004 \\
\hline
\end{tabular}

Based on the table, $B=$ Beta value, $t=t$ value and Sig. $=P$ value. A hypothesis are made based on the coefficient result on the table 4.33 .

\section{Hypothesis for Job Satisfaction}

Coefficient result above shows the Job Satisfaction beta value of 0.051 with $t$ value of 0.446 and $P$ value of 0.658 . This indicate that the hypothesis for Job satisfaction have a positive relationship with Visionary Leadership but all of the value does not comply with the coefficient indicator. So, the hypothesis is rejected.

\section{Hypothesis for Employee Engagement}

Coefficient result above shows the Employee Engagement beta value of 0.406 with $t$ value of 2.256 and $P$ value of 0.29 . This indicate that the hypothesis for Employee Engagement have positive relationship with Visionary Leadership. The hypothesis is accepted.

\section{Hypothesis for Employee Attitude}

Coefficient result above shows the Employee Attitude beta value of 0.430 with $t$ value of 3.034 and $P$ value of 0.004 . This indicate that the hypothesis for Employee Attitude has a positive relationship with Visionary Leadership. The hypothesis is accepted.

\section{Discussion}

Based on the research, the researcher found that the effect of leadership styles on employee's performance in Pos Laju courier services company is ultimately important and very useful. This study can be used by Pos Laju courier service company in order to improve their higher management leadership ability to ensure that they can provide a better organization future and services to customer and also can achieve the organization goals. Pos Laju higher management should use this visionary leadership ability that could influence on their employees to ensure a better affection toward employees performance.

The research analysis have stated that R2 represented $93.3 \%$ of variation in employee's performance due to independent variable. Only three independent variable listed in the employee's performance. From the analysis result, the three main variable in employee performance have a positive relationship to the visionary leader which is job satisfaction, employee engagement and employee attitude.

Even all variable have positive relationship, the hypothesis have rejected Job Satisfaction variable due to it not comply with the indicator from the coefficients analysis. Only two hypothesis that have affected by the visionary leadership which is on the Employees Engagement and Employee Attitude. This shown that the effective of visionary leadership have influenced the employee engagement and employee attitude positively.

The researcher will give a few recommendation to improve the visionary leadership and on employee performance especially for job satisfaction in Pos Laju company. This is to give better influenced and improve every ability and performance.

Based on the main variable on job satisfaction, a positive relationship from the higher management will contribute to a better working condition for employees to feel satisfied. Visionary leader still can influence employee even they doesn't have good relationship between employees. So, this type of relationship can give more positive impact toward employee to perform at work and this will give a better achievement toward employee productivity.

In order to extract an effective visionary leader in every individual or on the higher management, a higher commitment is needed. This commitment can produce a high level of motivation that can contribute in helping to ensure goal achievement. Thus, the upper management could develop better visionary leader if they committed to comply with the decision above.

Leadership is not just a behavior, it is a people job. When an employee want to talk with the higher management for whatever reason, they need to make sure to set aside time to do so and focus on them. So far there to many higher management communicate or make time for their employees far too little. There should have a continuous interaction between employer and employee to ensure they really deserve more than meaningless communication. 
One aspect that you cannot argue with is facts of a data. There's a power in number. Any higher management can use overall performance analytics in any organization as a guidance to make a decision to measure on employee's performance. By giving a good method, employees will give respect and value you're logical. There is nobody wants to work for someone that make a subjective decision without thinking about the value around them.

For a conclusion on this research study, it can conclude that the variable in Employee Performance which the Job Satisfaction, Employee Engagement and Employee Attitude have a positive relationship with Visionary Leadership but only two hypothesis is accepted which on employee engagement and employee attitude. The R2 represent $93.3 \%$ of variation in employees performance was due to independent variable. The study on effect of leadership styles on employee performance can ensure the improvement and better leadership influence on the higher management in every organization to have a better affection. This study can help the Pos Laju courier services company to know their weaknesses and disadvantages on their leadership ability at the same time they can do the improvement on the weaknesses.

\section{References}

Adair, J. (2015). Not bosses but leaders: How to lead the way to success. Jersey New: MPG book Limited.

Ali, A., Saleem, S., Bashir, M., Riaz, W., \& Sami, A. (2018). Mediating Role of Citizens' Participation between Public Service Motivation, Political Interference and Local Government Performance: A Case Study of Municipalities of Punjab. Abasyn Journal of Social Sciences-Special Issue: AIC 2017, 250-264

Amoaka, A. R. (2008). The seven habits of highly effective people: restoring the character ethic. New York: Fireside Book.

Armstrong, M. (2004). Human Resource Management Theory and Practice. London: Bath Press Ltd. 16, 273-285.

Armstrong. (2012). Factors Affecting Job Performance. Journal of Social Sciences, Humanities, and Arts, Silpakorn University., 6-15.

Avolio, B.J. (2009). Examining the relationship of leadership and physical distance with business unit performance. The Leadership Quarterly, 16, 273-285.

Awan, M. (2009). Examining the Relationships with Full Range Leadership Model, Employee Outcomes, and Organizational Culture. Ethical Leadership, 4-9.

Bass B. M. and Avolio B. J, (2009) Developing transformational leadership: 1992 and beyond, Journal of European Industrial Training, 14, 21-27.

Carter M (2008) Overview of leadership in organization.

Chen, S. H. (2010). The influence of leadership expertise and experience on organizational performance: a study of Amanah Ikhtiar Malaysia. Asia Pacific Business Review, 16(1-2), pp. 59-77.

Iqbal N, Anwar S, Haider N (2015) Effect of Leadership Style on Employee Performance. Arabian J Bus Manage Review 5:146.

Iqbal, N. A. (2015). Not bosses but leaders: How to lead the way to success. . Jersey New: MPG book Limited.

Jackson, W, \& Sneijder. (2009).“Organizational Learning, Innovation and Performance: A Study of Malaysian Small and Medium Sized Enterprises,'International Journal of Business and Management Vol. 6, No. 12.

Maxwell, John. (2002): The 21 Irrefutable Laws of Leadership Work Book, Thomas Nelson publishers, New York.

McBride. (2002), Examining the Relationship between Leadership and Emotional Intelligence in Senior Level Managers, Leadership and Organization Development Journal; 23(2), 66-78.

Mosadehgrad (2008). The leadership challenge: How to get extraordinary things done in organizations. San Francisco, Washington, London: Jossey-Bass Inc, Publishers.

Musamaruka, A, I, (2015)."Effects of innovation types on firm performance", International Journal of Production Economics, Volume 133, Issue 2.

Northcutt, S., (2009). SANS Leadership and Management Competencies. Bethesda: The SANS Institute.

Reiley, S. (2009). Leading From the Sandbox. Leadership and Mobilizing Potential, Human Resource Management. International Journal of Global Business; 10(1): 8-16.

Rizwan, J (2016). Leadership in Organization, current Issues and Key Trends, $60,541-572$.

Sami, A., Jusoh, A., \& Qureshi, M. I. (2016). Does Ethical Leadership Create Public Value? Empirical Evidences from Banking Sector of Pakistan. International Review of Management and Marketing, 6(4S).
Shafie, et, al. (2013). Leadership style, organizational culture and performance: Empirical evidence from UK companies. International Journal of Human Resources Management, 11(4), 766-788.

Shneider, F. (2009) Defining Servant Leadership: A Recommended Typology for Servant Leadership Studies, Servant Leadership Roundtable, August, pp1 12

Walumbwa, F. O. (2009). Moderating role of follower characteristics with transformational leadership and follower engagement. Group \& Organization Management, 34 (5), 590-619. 